\title{
Ontogenetic changes in dietary carbon sources and trophic position of two co-occurring horseshoe crab species in southwestern China
}

\author{
Lan-Feng Fan ${ }^{1,2}$, Chang-Po Chen ${ }^{1,2, * *}$, Ming-Che Yang ${ }^{2}$, Guanglong Qiu ${ }^{1}$, \\ Yong-Yan Liao ${ }^{3,4}$, Hwey-Lian Hsieh ${ }^{2, *, * *}$ \\ ${ }^{1}$ Guangxi Mangrove Research Center, Guangxi Academy of Sciences, Beihai 536000, PR China \\ ${ }^{2}$ Biodiversity Research Center, Academia Sinica, Nankang, Taipei, Taiwan 115, ROC \\ ${ }^{3}$ Ocean School of Qinzhou University, Qinzhou 535000, PR China \\ ${ }^{4}$ Guangxi Key Laboratory of Beibu Gulf Marine Biodiversity Conservation, Qinzhou University, Qinzhou 535000, PR China
}

\begin{abstract}
Understanding which food sources are nutritionally important at nursery grounds is critical in the conservation of the dwindling populations of horseshoe crabs in Asia. We used $\delta^{13} \mathrm{C}$ and $\delta^{15} \mathrm{~N}$ values to define life-stage changes in dietary carbon sources and trophic position of 2 co-occurring horseshoe crab species, Tachypleus tridentatus and Carcinoscorpius rotundicauda, in a mangrove- and seagrass-vegetated estuary, Pearl Bay, in Guangxi, China. $\delta^{13} \mathrm{C}$ signatures in tissues of $T$. tridentatus and C. rotundicauda varied between species and among life stages within species, with the greatest differences occurring among earlier life stages (instars 5-7; 20-30 mm prosomal width). Life-stage specific diets were consistent with known habitat use by the 2 horseshoe crab species, with $T$. tridentatus reflecting slightly enriched seagrass carbon sources and C. rotundicauda reflecting influences of lighter sediment particulate organic matter $\left(\mathrm{POM}_{i}-15.1\right.$ vs. -15.8\%). Overall, seagrass contributed most to dietary carbon of both species $(\sim 60 \%)$, followed by sediment POM $(35 \%) . \delta^{15} \mathrm{~N}$ signatures were similar between species $(\sim 11.6 \%)$, with $C$. rotundicauda adults exhibiting a slightly more enriched signal than juveniles (12.7 vs. $11.6 \%$ ), and all horseshoe crabs occupied secondary consumer trophic levels. The $\delta^{15} \mathrm{~N}$ signatures in horseshoe crabs at Pearl Bay were lighter than those from more urbanized waters, likely due to lower anthropogenic nitrogen loading. Our data and those of previous studies suggest that effective international and national strategies for conserving threatened Asian horseshoe crabs would benefit from incorporating efforts to protect seagrass and mangrove habitats.
\end{abstract}

${ }^{*}$ Corresponding author: zohl@gate.sinica.edu.tw

${ }^{* *}$ Authors contributed equally to this paper

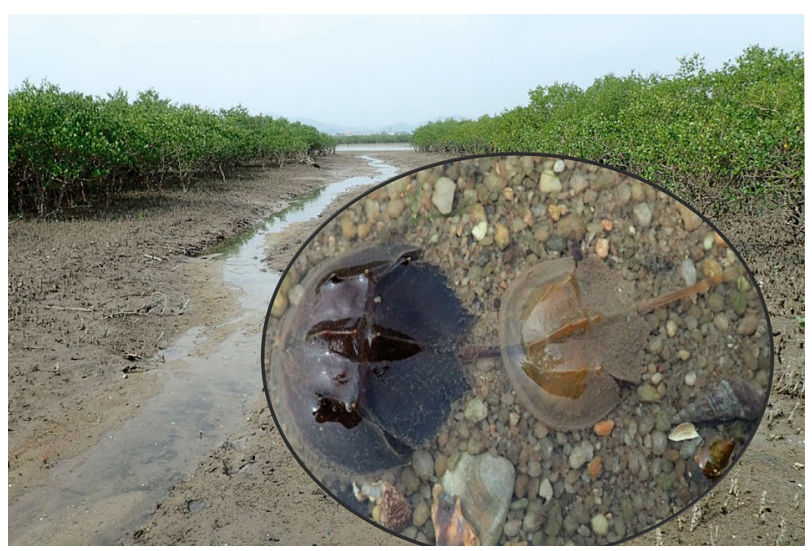

Newly molted juvenile horseshoe crab (left) and its old shell (right) on a tidal flat adjacent to mangroves in the Pearl Bay estuary (Guangxi, China).

Photo: Chang-Po Chen

KEY WORDS: Horseshoe crabs - Life stages . Seagrass $\cdot$ Mangrove $\cdot \delta^{13} \mathrm{C} \cdot \delta^{15} \mathrm{~N}$

\section{INTRODUCTION}

The 3 Asian horseshoe crab species Tachypleus tridentatus, T. gigas, and Carcinoscorpius rotundicauda once thrived on the coasts of the South and East China Seas, but have severely declined due to loss of coastal habitats and high harvesting levels for Tachypleus amoebocyte lysate and for human consumption (Chen et al. 2015 and references therein).

() The authors 2017. Open Access under Creative Commons by Attribution Licence. Use, distribution and reproduction are unrestricted. Authors and original publication must be credited. 
There is concern that these renowned 'living fossil' populations may be decimated if no effective actions are taken to protect them (IUCN 2012, P. K. S. Shin unpubl. data). International conservation strategies have urged studies that strengthen the cause for legal protection of these species' critical habitats, including defining and characterizing their nursery, foraging and spawning sites (IUCN 2012).

Tidal flats in mangrove- and seagrass-vegetated estuarine bays are critical nursery grounds for juveniles of the horseshoe crabs $T$. tridentatus and $C$. rotundicauda, as seen in Hong Kong (Shin et al. 2009, Morton \& Lee 2010) and in the eastern and western parts of the Beibu Gulf, Guanxi, China (Hu 2011, Chen et al. 2015). Mangroves are also essential habitats for adult $C$. rotundicauda, as this species spends its entire life in mangrove-vegetated bays (its common name is mangrove horseshoe crab). In estuarine and coastal food webs, however, mangrove detritus was found to be less important to nutrition than seagrass detritus and benthic diatoms for the majority of macrobenthos (Rodelli et al. 1984, Newell et al. 1995, Hsieh et al. 2002). Mangrove detritus was found in the diet of some species, such as juvenile prawns, grapsid crabs, and gastropods (Rodelli et al. 1984, Newell et al. 1995), suggesting that mangroves provide an, as yet, undefined nutritional value to some species. Understanding the relative contribution of these different potential food sources at the basal primary producer level for horseshoe crabs in their critical habitats is an important step in the conservation of these species (IUCN 2012, Chen et al. 2015).

Many consumers, including some horseshoe crab species, undergo life-stage changes in diets (Hentschel 1998, Gaines et al. 2002), with trophic positions being elevated as body size or weight increases (France et al. 1998, Rau et al. 1981). Studies on the diet of the American horseshoe crab Limulus polyphemus showed that the younger instars (2nd and 3rd) derived food from benthic and suspended particulate organic matter (POM), while later instars (5th to 11 th) consumed polychaetes and crustaceans, and adults preyed on bivalves and gastropods (Gaines et al. 2002, Carmichael et al. 2009). Because horseshoe crabs molt to grow, size-at-age relationships (life stages) are distinct prior to reaching maturity (Sekiguchi 1988, Chen et al. 2004). While Asian horseshoe crab species have different specific sizesat-age compared to American horseshoe crabs (Sekiguchi 1988), they may have comparable feeding ecology, being herbivores or detritivores during early stages and becoming increasingly predatory as they age and grow. Comparable data on the instar or size- related diets of Asian horseshoe crab species are needed to establish these relationships.

Most data on diet of Asian horseshoe crab species come from analyses of a few discrete groups at different locations. Benthic diatoms were found to contribute to the diet of $C$. rotundicauda and T. gigas living on non-vegetated mud- and sandflats in Malaysia (Newell et al. 1995), while seagrass-derived organic matter was the major carbon source of juvenile T. tridentatus and C. rotundicauda living in the eastern part of the Beibu Gulf, China (Hu 2011). In contrast, the diets of juvenile $T$. tridentatus living in a mangrove- and seagrass-vegetated site in Hong Kong consisted of a mixture of small invertebrates, supported by seagrass biomass (Kwan et al. 2015). Earlier studies reported that benthic invertebrates were the common food of juvenile T. tridentatus and $C$. rotundicauda as well as sub-adult and adult $T$. gigas (Chatterji et al. 1992, Zhou \& Morton 2004). Additional study is needed across a range of age classes to determine the relative importance of the different primary producers supporting the base of food webs for Asian horseshoe crab species within their various habitats.

On the tidal sand- and mudflats of Pearl Bay, an estuarine bay in the western Beibu Gulf, Guangxi, southwestern China, juvenile T. tridentatus and juvenile and adult $C$. rotundicauda co-occur (Chen et al. 2015). This bay is predominately vegetated by mangroves and patchily distributed seagrasses. Within this area, the microhabitat characteristics differ between the 2 horseshoe crab species. T. tridentatus is more abundant seaward and lives on poorly sorted sediments, whereas juvenile $C$. rotundicauda aggregates at the edges of the mangrove forest in more landward areas and lives on sediments with greater organic carbon and silt-clay content (Chen et al. 2015). Given that various primary producers are available within the bay along with the potential for horseshoe crab diets to vary with size, species, and location within and between habitats (Newell et al. 1995, Gaines et al. 2002, Hsieh et al. 2002, Carmichael et al. 2004, Kwan et al. 2015), the cooccurrence of the 2 horseshoe crab species in Pearl Bay provides an ideal setting to determine the relative contribution of different primary producers to the assimilated diet of these Asian horseshoe crab species at different life stages.

The purpose of the present study was to (1) define the carbon sources at the base of the food web and (2) determine how trophic positions and carbon sources change with different life stages of the 2 co-occurring horseshoe crab species T. tridentatus and C. rotundi- 
cauda in Pearl Bay, Guangxi, China. We measured $\delta^{13} \mathrm{C}$ and $\delta^{15} \mathrm{~N}$ signatures in available basal food sources, including mangrove, seagrass, and sedimentary particulate organic matter and in different instar stage of each species at 2 locations in the Bay.

\section{MATERIALS AND METHODS}

\section{Study area}

Pearl Bay is located on the west coast of the Beibu Gulf, Guangxi, southwestern China (Records of bays in China 1993). The bay covers a total area of $94.2 \mathrm{~km}^{2}$, with the coastline stretching approximately $46 \mathrm{~km}$. The bay opens into Beibu Gulf at its southern end (Fig. 1). The northwestern and western regions of the Bay are fed with freshwater from the Jiangping River, which runs through dense mangroves at Jiaodong and Shanxin. The distance between the mouth of the Jiangping River and the mouth of the bay is approximately $6.3 \mathrm{~km}$. The tidal sand- and mudflats in the bay are large and generally extend
2 to $3 \mathrm{~km}$ when tides recede, providing habitats for numerous economically important invertebrates, including horseshoe crabs (Chen et al. 2015). The mangrove forests in Jiaodong and Shanxin cover approximately $5.44 \mathrm{~km}^{2}$ (Guangxi Mangrove Research Center unpubl. data) and are dominated by Aegiceras corniculatum and Avicennia marina, with some Bruguiera gymnorrhiza and Kandelia obovata. Beds of seagrass Halophila beccarii are distributed in patches on the tidal flats, along tidal creeks, and along the seaward edges of the mangrove forests, with possible distribution into the shallow reaches of the bay. Beds of seagrass Zostera japonica are also distributed on the tidal flats along the seaward edges of the mangrove forests but are typically found at higher tidal zones than H. beccarii (Qiu et al. 2013, 2014a).

\section{Sampling design}

Juvenile Tachypleus tridentatus and juvenile and adult Carcinoscorpius rotundicauda horseshoe crabs, with sizes at prosomal carapace width ranging from
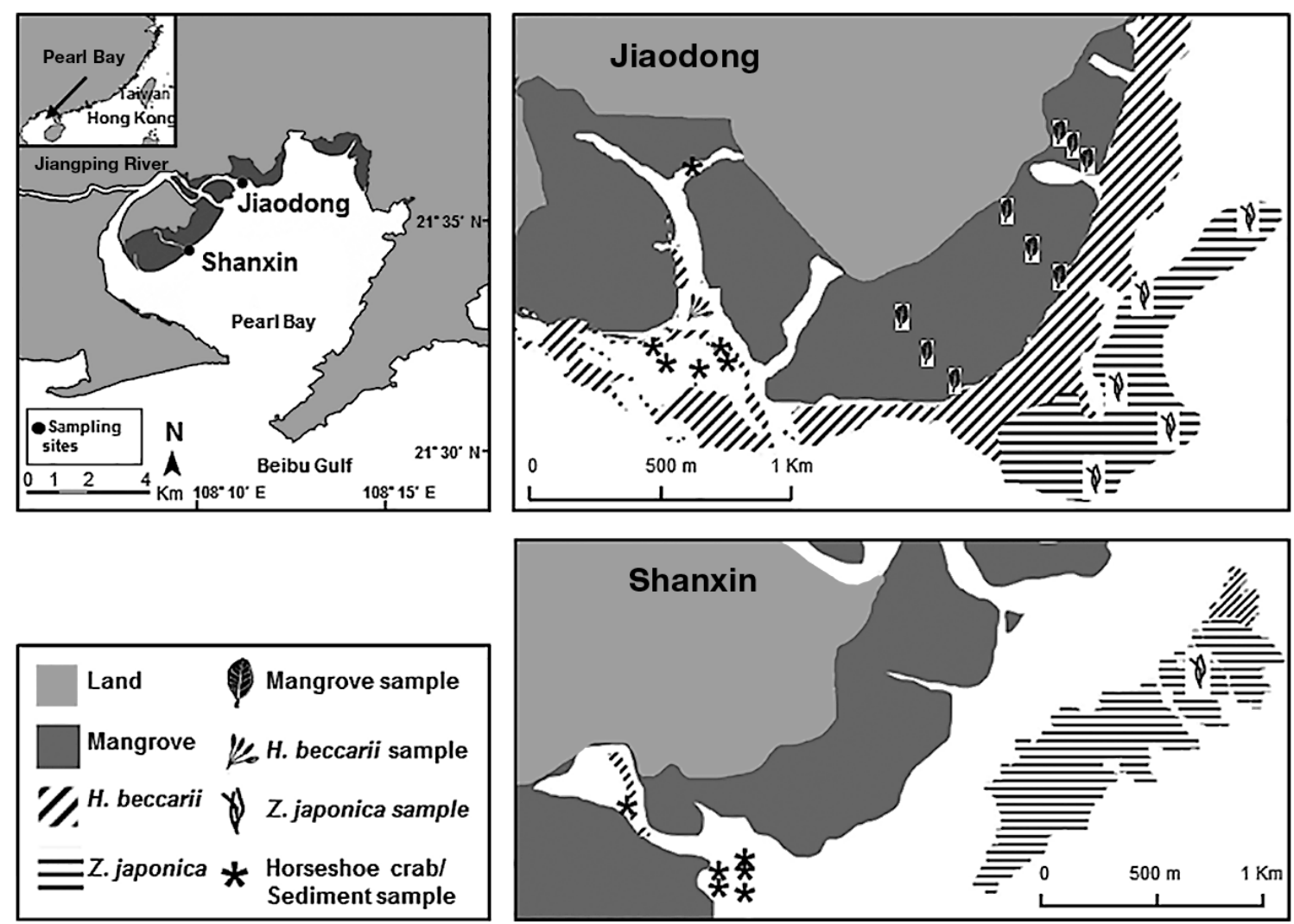

Fig. 1. Study area in Pearl Bay on the west coast of Beibu Gulf, Guangxi, southwestern China, showing sampling sites of the 2 horseshoe crab species (Tachypleus tridentatus and Carcinoscorpius rotundicauda), sediment organic matter, seagrass and mangroves, and extent of seagrass beds (Zostera japonica and Halophila beccarii) and mangrove vegetation 
$16-74 \mathrm{~mm}$ in juveniles and $121-156 \mathrm{~mm}$ in adults (Table A1 in the Appendix), were sampled from the tidal flat at Jiaodong and Shanxin in Pearl Bay during low tides on 23-25 October 2014 (Fig. 1). Two sites were sampled to provide a sufficient number of individuals of each species at different life stages. Juveniles $>1 \mathrm{~cm}$ in carapace length (head to tail) were collected from the sediment surface during low tide and identified to the species level (Chen et al. 2015).

To sample mangroves and seagrass species, we used samples collected by Qiu et al. (2014b) at the same Jiaodong site during April to May 2011, including 4 mangrove species (Aegiceras corniculatum, Avicennia marina, B. gymnorrhiza, K. obovata) and the seagrass species $Z$. japonica (Fig. 1). Additional samples of $Z$. japonica and $H$. beccarii were collected from Jiaodong and Shanxin in December 2015 (Fig. 1). Senescent leaves of mangroves and fresh above-ground parts of seagrasses were hand-picked in the field. Collection dates for plants were during the growing season (April to December) along the Guangxi coasts to minimize temporal variations in isotopic compositions due to plant growth conditions. Our data also showed that mean $( \pm \mathrm{SD}) \delta^{13} \mathrm{C}$ values of $Z$. japonica varied little between years (April 2011 vs. December 2015: $-13.4 \pm 0.7 \%, \mathrm{n}=12$ vs. $-13.5 \pm$ $0.1 \%, \mathrm{n}=6$; Wilcoxon 2-sample test, $Z=0, \mathrm{p}=1.00$ ); thus, the data of these 2 batches were pooled for the subsequent analyses.

POM was collected from the sediment using an acrylic corer (diameter $2.6 \mathrm{~cm}$ ) and taking the top $3 \mathrm{~cm}$ of sediment from the tidal flats at the 2 sites (Fig.1). Large pieces of animal and plant tissues were removed before analyses. Cores were kept on ice during transportation. Replicates of each sample type, ranging from 4 to 53 samples (Table A2 in the Appendix), were collected and treated individually in the subsequent analyses.

\section{Determination of instar stages}

Instar stages were determined from size-associated growth curves and by making comparisons with established reference data sets and known growth increments from previous studies. Body size was determined by measuring prosomal carapace width (hereafter referred to as prosomal width) to the nearest $0.1 \mathrm{~mm}$ with Vernier calipers for all sampled crabs. Size-associated curves were constructed by plotting prosomal width against the accumulated number of individuals at a given size, to visualize the discrete growth increments among groups of indi- viduals up to instar 6. The resulting groups (individuals of a common size-at-age) were assigned to instars by comparing sizes to reference data from H.-L. Hsieh and C.-P. Chen (unpubl. data), who traced the growth of tagged instars individually in the laboratory (Table A1), for juvenile T. tridentatus and from Zadeh et al. (2009, Table A1) for C. rotundicauda. The consistent size increment ratio between 2 consecutive instars $(1.31 \pm 0.06 \%$ [mean $\pm \mathrm{SD}]$ for $T$. tridentatus, H.-L. Hsieh and C.-P. Chen unpubl. data; $1.36 \pm 0.02 \%$ for C. rotundicauda, Zadeh et al. 2009) was used to predict advanced instar stages ( $>6$ th) in the 2 species. This approach was useful because size-at-age relationships for older juveniles are often ambiguous due to the horseshoe crabs' slow growth and long lifespan (Sekiguchi 1988).

\section{Sample preparation and analyses of stable carbon and nitrogen isotopes}

Muscle tissue was dissected from legs of each sampled horseshoe crab and rinsed in double-distilled water. Seagrass and mangrove leaves were cleaned using clean seawater to remove adhered macroalgae, epifauna or insects. Muscle and sediment POM were frozen at $-70^{\circ} \mathrm{C}$, freeze-dried (Virtis $2 \mathrm{~K}$ ), thoroughly homogenized by grinding with mortar and pestle, acidified with $1 \mathrm{~N} \mathrm{HCl}$ to remove carbonates, rinsed in distilled water, and freeze-dried and homogenized again. Plant leaves were similarly treated except that they were oven-dried at $40^{\circ} \mathrm{C}$ for $24 \mathrm{~h}$ prior to homogenization.

The stable isotope ratios of carbon and nitrogen in muscle tissue, $Z$. japonica and $H$. beccarii leaves collected in 2015, and sediment POM were measured using a Finnigan MAT 253 mass spectrometer (Thermo Finnigan) coupled to a Flash 2000 elemental analyzer (Thermo Fisher) for combustion and automated analysis, linked using a Conflo IV Universal Interface (Thermo Fisher). Stable isotope ratios in mangrove and $Z$. japonica leaves collected in 2011 by Qiu et al. (2014b) were measured with a Thermo Finnigan Delta Plus mass spectrometer coupled to a Euro EA3000 elemental analyzer (EuroVector) and linked using a Conflo III Interface (Thermo Finnigan).

Stable isotope ratios were reported in standard notation as: $\delta \mathrm{X}(\%)=\left[\left(\mathrm{R}_{\text {sample }} / \mathrm{R}_{\text {standard }}\right)-1\right] \times 10^{3}$, where $\mathrm{X}$ is ${ }^{13} \mathrm{C}$ or ${ }^{15} \mathrm{~N}$ and $\mathrm{R}={ }^{13} \mathrm{C} /{ }^{12} \mathrm{C}$ or ${ }^{15} \mathrm{~N} /{ }^{14} \mathrm{~N}$. Standard reference materials for carbon and nitrogen included Pee Dee belemnite and atmospheric nitrogen, respectively. The working standard materials, including USGS24 (mean \pm SD: $\delta^{13} \mathrm{C}=-15.90 \pm$ 
$0.25 \%$ ) for carbon and USGS40 $\left(\delta^{15} \mathrm{~N}=-4.52 \pm\right.$ $0.06 \%$ ) for nitrogen, were also used. The precision of the measurements was $\pm 0.1 \%$ for $\delta^{13} \mathrm{C}$ and $\pm 0.2 \%$ for $\delta^{15} \mathrm{~N}$. Unless otherwise indicated, the values of prosomal width $(\mathrm{mm})$ and $\delta^{13} \mathrm{C}$ and $\delta^{15} \mathrm{~N}(\%)$ of all samples are given as mean $\pm \mathrm{SE}$.

\section{Determining carbon sources and trophic positions among instars}

The carbon sources and trophic positions of T. tridentatus and C. rotundicauda were analyzed using the mean values of $\delta^{13} \mathrm{C}$ and $\delta^{15} \mathrm{~N}$ of the horseshoe crabs at each determined instar and adult stage. To examine which carbon sources contributed to the horseshoe crabs' diet and in which proportions, we applied a hierarchical Bayesian mixing model (MixSIAR v3.1; Stock \& Semmens 2013) using the mean and SD of both $\delta^{13} \mathrm{C}$ and $\delta^{15} \mathrm{~N}$ signatures of primary producers, sediment POM, and the consumer horseshoe crabs. Using MixSIAR, we specified Markov chain-Monte Carlo parameters with 3 chains over 300000 iterations, removing the first 200000 iterations as burn-in and thinning by a factor of 100 (Stock \& Semmens 2013). The advantage of using a Bayesian mixing model is that it incorporates natural variation and uncertainty associated with the data into the model and generates more accurate probability estimates of source proportions (Parnell et al. 2010). The primary producers used in the mixing model included 4 mangrove species (Aegiceras corniculatum, Avicennia marina, K. obovata, and B. gymnorrhiza) and 2 seagrass species ( $Z$. japonica and $H$. beccarii). The first 3 mangrove species listed above were grouped due to their similar signatures $\left(\delta^{13} \mathrm{C}:-29.1 \pm 0.2 \%, \delta^{15} \mathrm{~N}: 5.8 \pm 0.1 \%\right.$, Table A2) and referred to as Mangrove I, while B. gymnorrhiza $\left(\delta^{13} \mathrm{C}:-29.4 \pm 0.4 \%\right.$, $\delta^{15} \mathrm{~N}: 4.1 \pm 0.4 \%$, Table A2) was called Mangrove II.

Given that most juvenile horseshoe crabs are estimated to be secondary consumers and up to 2 trophic levels above the basal level (Gaines et al. 2002, Kwan et al. 2015), we applied $+1.6 \%$ fractionation (trophic enrichment factor) in the $\delta^{13} \mathrm{C}$ signature and $+6 \%$ fractionation in the $\delta^{15} \mathrm{~N}$ signature to the 2 horseshoe crab species when using the MixSIAR model. We assumed $+0.8 \%$ fractionation for $\delta^{13} \mathrm{C}$ and $+3 \%$ fractionation for $\delta^{15} \mathrm{~N}$ per trophic shift from diet to consumer (Peterson \& Fry 1987). Percent contributions of the 5 basal food sources (2 mangrove categories, 2 seagrass species and POM) to the horseshoe crabs were reported as median diet proportions (50\% quantiles of all potential food source combinations). To assess changes in these trophic patterns across locations on the coasts of the South China Sea, we compared our data to published $\delta^{13} \mathrm{C}$ and $\delta^{15} \mathrm{~N}$ values for $C$. rotundicauda or $T$. tridentatus, measured in peninsular Malaysia (Newell et al. 1995), eastern Beibu Gulf (Hu 2011), and Hong Kong adjacent to the Pearl River Delta (Kwan et al. 2015).

In the present study, trophic positions were inferred based on the levels of $\delta^{15} \mathrm{~N}$ signatures only. Numerical values for trophic position were not estimated for T. tridentatus and C. rotundicauda due to the lack of an established baseline from local primary consumers (Post 2002). Instead, we estimated the baseline using the $\delta^{15} \mathrm{~N}$ values of local primary producers, assuming that consumers were in the same trophic position when $\delta^{15} \mathrm{~N}$ values differed by $<3 \%$ (Peterson \& Fry 1987).

\section{Statistical analyses}

The effects of species on the horseshoe crabs' body size, measured as the prosomal width, and the crabs' $\delta^{13} \mathrm{C}$ and $\delta^{15} \mathrm{~N}$ signatures were compared using the 1-way Wilcoxon 2-sample test (Hollander \& Wolfe 1999). Life-stage changes in the $\delta^{13} \mathrm{C}$ and $\delta^{15} \mathrm{~N}$ signatures of the horseshoe crabs were examined using the 1-way Kruskal-Wallis test (Hollander \& Wolfe 1999). When significant results were found, multiplemeans comparison among different instar stages using Dunn's test were performed (Hollander \& Wolfe 1999). The difference in the $\delta^{15} \mathrm{~N}$ signatures between adult and juvenile $C$. rotundicauda was examined using a 1-way Wilcoxon 2-sample test. All statistical analyses were performed using the SAS 9.1 software package (SAS Institute 2003).

\section{RESULTS}

\section{Body sizes and instar stages}

A total of 62 juvenile Tachypleus tridentatus and 109 juvenile and 3 adult Carcinoscorpius rotundicauda were collected. The growth curves of $T$. tridentatus and C. rotundicauda (based on their prosomal width and reference data) indicated that, at the same instar stage, T. tridentatus was larger than C. rotundicauda (Table 1, Fig. 2). However, there were no significant species effects on juveniles' prosomal width (Table 2). T. tridentatus jueniles represented 6 instar stages that spanned from instars 5 to $10(21.5 \pm$ 
Table 1. Life-stage changes of the prosomal width (PW) and $\delta^{13} \mathrm{C}$ and $\delta^{15} \mathrm{~N}$ signatures through the instar stages of Tachypleus tridentatus and Carcinoscorpius rotundicauda studied in Pearl Bay, Guangxi, China. Data are combined from the 2 sites, Jiaodong and Shanxin. Values are mean $\pm \mathrm{SE}, \mathrm{n}=$ sample size

\begin{tabular}{|lcccc|}
\hline Instar & $\mathrm{n}$ & $\mathrm{PW}(\mathrm{mm})$ & $\delta^{13} \mathrm{C}(\%)$ & $\delta^{15} \mathrm{~N}(\%)$ \\
\hline \multicolumn{5}{c}{ Tachypleus tridentatus } \\
5 & 2 & $21.5 \pm 1.6$ & $-14.2 \pm 0.2$ & $11.7 \pm 0.1$ \\
6 & 9 & $28.1 \pm 0.7$ & $-14.6 \pm 0.1$ & $11.4 \pm 0.1$ \\
7 & 5 & $36.3 \pm 0.7$ & $-15.0 \pm 0.1$ & $11.8 \pm 0.1$ \\
8 & 10 & $44.3 \pm 1.8$ & $-15.7 \pm 0.3$ & $11.6 \pm 0.1$ \\
$9-10$ & 7 & $64.3 \pm 1.5$ & $-15.4 \pm 0.3$ & $11.7 \pm 0.1$ \\
Overall & 33 & $41.5 \pm 2.5$ & $-15.1 \pm 0.1$ & $11.6 \pm 0.1$ \\
Carcinoscorpius rotundicauda & & \\
6 & 4 & $19.0 \pm 0.8$ & $-16.3 \pm 0.1$ & $11.2 \pm 0.2$ \\
7 & 12 & $23.9 \pm 0.6$ & $-15.8 \pm 0.3$ & $11.5 \pm 0.1$ \\
8 & 17 & $33.6 \pm 0.4$ & $-15.1 \pm 0.2$ & $11.6 \pm 0.1$ \\
9 & 5 & $44.4 \pm 0.7$ & $-15.6 \pm 0.7$ & $11.9 \pm 0.3$ \\
10 & 9 & $57.1 \pm 1.8$ & $-16.2 \pm 0.5$ & $11.7 \pm 0.1$ \\
11 & 3 & $72.4 \pm 0.9$ & $-16.5 \pm 0.7$ & $11.5 \pm 0.2$ \\
$12+13$ (adult) & 3 & $141.0 \pm 10.4$ & $-16.6 \pm 0.2$ & $12.7 \pm 0.5$ \\
Overall & 53 & $43.6 \pm 3.9$ & $-15.8 \pm 0.2$ & $11.6 \pm 0.1$ \\
\hline \multicolumn{6}{c}{} & & & & \\
\hline
\end{tabular}

1.6 to $64.3 \pm 1.5 \mathrm{~mm}$ prosomal width). C. rotundicauda represented 6 juvenile instar stages, from instars 6 to $11(19.0 \pm 0.8$ to $72.4 \pm 0.9 \mathrm{~mm})$, and an adult stage represented by instars 12 and 13 (141.0 \pm $10.4 \mathrm{~mm}$ ). Instar 12 was a male crab, whereas instar 13 were females. Data from the putative 9th and 10th instars in $T$. tridentatus were combined due to an unclear abrupt growth increment between the 2 stages (Fig. 2, Tables 1 \& A1).

\section{$\delta^{13} \mathrm{C}$ and $\delta^{15} \mathrm{~N}$ signatures in horseshoe crabs}

Stable isotope ratios in $T$. tridentatus ranged from -15.7 to $-14.2 \%$ for $\delta^{13} \mathrm{C}$ and 11.4 to $11.8 \%$ or $\delta^{15} \mathrm{~N}$ among instars 5 to 10 (Table 1). Compared to T. tridentatus, values in $C$. rotundicauda were significantly lighter for $\delta^{13} \mathrm{C}$ (range: -16.6 to $-15.1 \%$ ) but similar for $\delta^{15} \mathrm{~N}$ (range: 11.2 to $12.7 \%$ ) among instars 6 to 13 (Tables $1 \& 2$ ).

The $\delta^{13} \mathrm{C}$ signatures in the 2 horseshoe crab species varied with instar stages (Fig. 3, Table 1). In T. tridentatus, the $\delta^{13} \mathrm{C}$ signatures decreased from $-14.2 \%$ at the 5 th instar to values between -15.7 and $-15.0 \%$ at

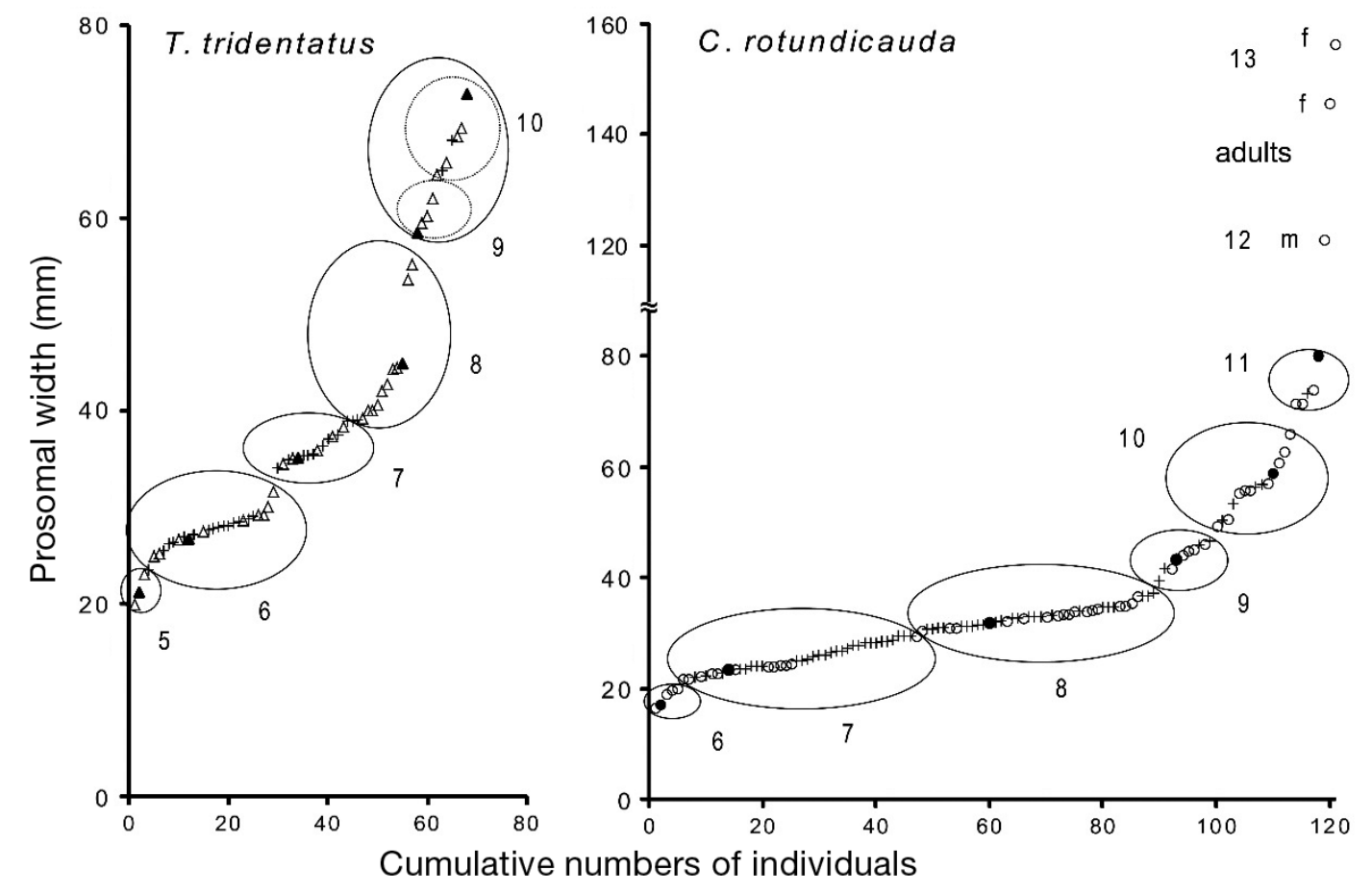

Fig. 2. Determination of the instar stages in Tachypleus tridentatus and Carcinoscorpius rotundicauda using size (prosomal width)-associated growth curves. Each of the large oval circles encloses a distinct instar stage. Numbers near the circles specify the instar stage. Data points, except solid triangles and solid circles, represent all samples collected in the field. Reference sizes with solid triangles (T. tridentatus) are from H.-L. Hsieh and C.-P. Chen (unpubl. data), and those with solid circles (C. rotundicauda) are from Zadeh et al. (2009). Determination of the instar stage of adults and the sizes of males (m) and females (f) in C. rotundicauda follow Sekiguchi et al. (1988). Data points with open triangles and open circles are subsamples used as a major data set for the detailed analyses in this study 
Table 2. Effects of species on the horseshoe crab prosomal width and $\delta^{13} \mathrm{C}$ and $\delta^{15} \mathrm{~N}$ signatures using the 1-way

Wilcoxon 2-sample test. ${ }^{*} \mathrm{p}<0.05$; ns: not significant

\begin{tabular}{|lccc|}
\hline Variable & df & $Z$ & $p$ \\
\hline Prosomal width & 1 & 1.42 & $0.156 \mathrm{~ns}$ \\
$\delta^{13} \mathrm{C}$ & 1 & 2.18 & $0.029^{*}$ \\
$\delta^{15} \mathrm{~N}$ & 1 & 1.36 & $0.173 \mathrm{~ns}$ \\
\hline
\end{tabular}

instars 7 to $10(\mathrm{p}<0.01$, Tables $1 \& 3)$. In C. rotundicauda, the size-related trend was not statistically significant $(\mathrm{p}>0.05$, Table 3$) . \delta^{13} \mathrm{C}$ signatures in $C$. rotundicauda were depleted at the 6th instar (ca. $-16 \%$ ), enriched to approx. $-15 \%$ at the 8 th instar, and gradually declined through the 9th to 11 th instars, reaching $-16.6 \%$ in adults (Fig. 3, Table 1). Overall, carbon sources for $T$. tridentatus were more enriched than those for $C$. rotundicauda at early instar stages (20-30 mm prosomal width), when the difference in $\delta^{13} \mathrm{C}$ values between species was ca. 1 to $2 \%$ (Table 1, Fig. 3). In addition, in C. rotundicauda, adults had higher $\delta^{15} \mathrm{~N}$ values than juveniles of either species (Table $1 ; Z=2.25$, p < 0.05).

\section{Defining basal carbon sources}

The $\delta^{13} \mathrm{C}$ and $\delta^{15} \mathrm{~N}$ signatures of the Mangrove I and II groups ranged from -29.4 to $-29.1 \%$ and 4.1 to $5.8 \%$, respectively (Table A2). The isotopic signatures of the seagrasses Zostera japonica and Halophila beccarii were enriched compared to mangroves, having mean values of $-13.4 \pm$ $0.1 \%$ and $-17.1 \pm 0.0 \%$ for $\delta^{13} \mathrm{C}$ and $7.1 \pm 0.3 \%$ and $10.0 \pm 0.1 \%$ o for $\delta^{15} \mathrm{~N}$, respectively. The $\delta^{13} \mathrm{C}$ and $\delta^{15} \mathrm{~N}$ values of the sediment POM were $-22.3 \pm 0.5 \%$ and $4.2 \pm 0.2 \%$, respectively.

Seagrass Z japonica-derived detritus contributed most to the diet of both species, comprising 62.6 and $58.6 \%$ (median) of the dietary carbon for $T$. tridentatus and C. rotundicauda, respectively (Table 4, Fig. 4). Sediment POM was the second-most important dietary carbon source, with median contributions of approx. 35\%, while mangrove sources accounted for $<3 \%$ of the diet of the 2 horseshoe crab species (median: 0.7 to $2.6 \%$, Table 4 ).
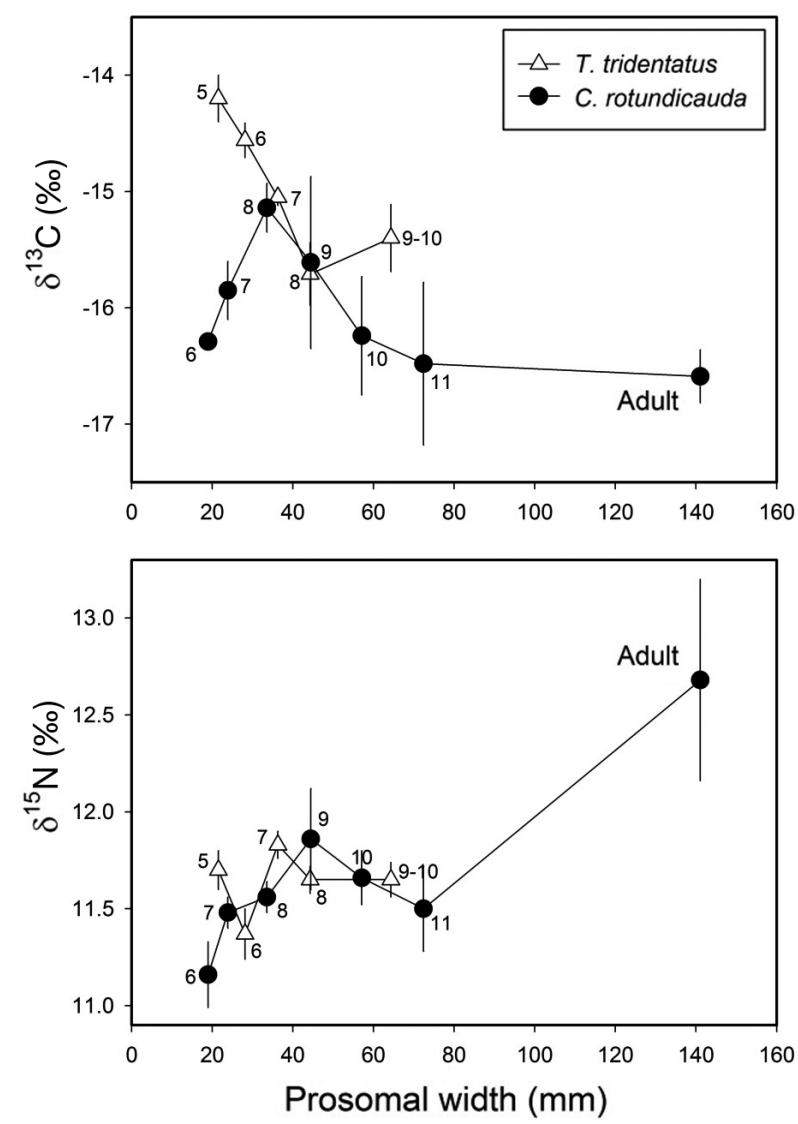

Fig. 3. Life-stage changes of the $\delta^{13} \mathrm{C}$ and $\delta^{15} \mathrm{~N}$ signatures with prosomal width (proxy of size) in horseshoe crabs Tachypleus tridentatus and Carcinoscorpius rotundicauda. Numbers represent instar stages. Vertical bars are $\pm 1 \mathrm{SE}$

Table 3. Comparisons of the life-stage changes in $\delta^{13} \mathrm{C}$ and $\delta^{15} \mathrm{~N}$ signatures (shown in Table 1) among instar stages of Tachypleus tridentatus and Carcinoscorpius rotundicauda using the Kruskal-Wallis test. For C. rotundicauda, data were analyzed including and excluding the adult stage. Multiple-means post-hoc comparisons for T. tridentatus $\delta^{13} \mathrm{C}$ signatures among instar stages were performed using Dunn's test. Means with the same letters are not significantly different. ${ }^{* *} \mathrm{p}<0.01$; ns: not significant

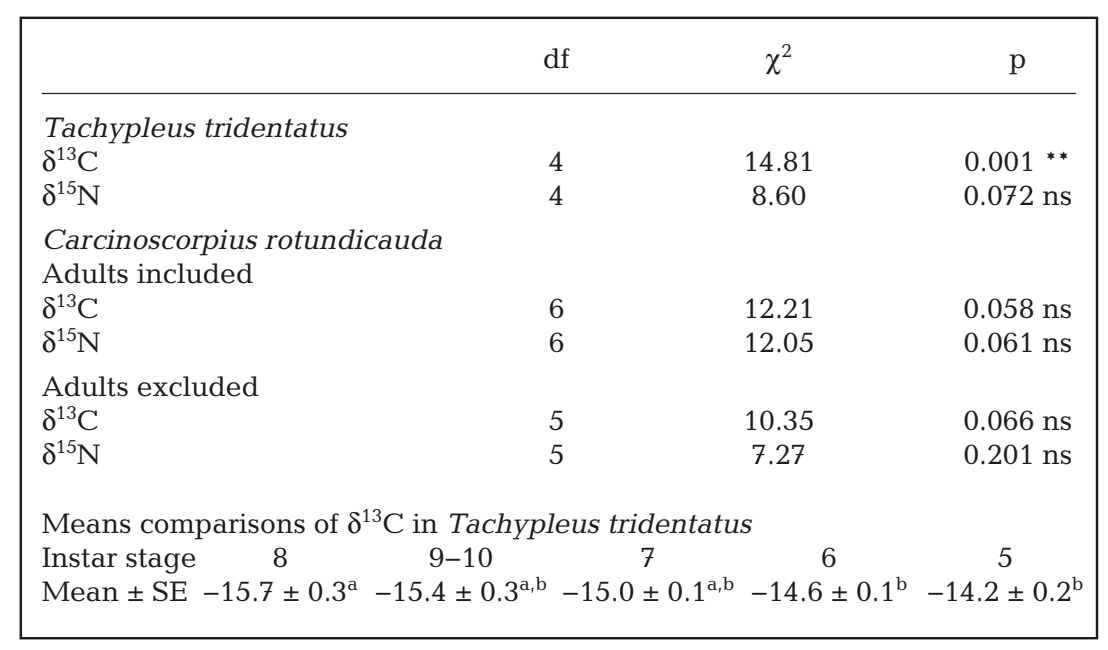




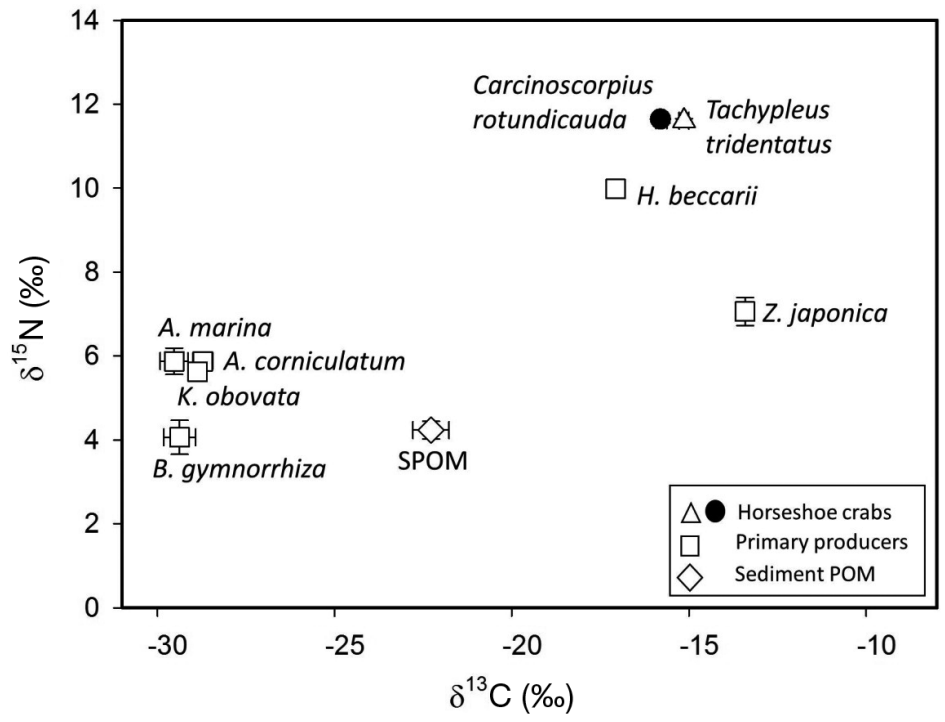

Fig. 4. Dual isotope plots of the $\delta^{13} \mathrm{C}$ and $\delta^{15} \mathrm{~N}$ signatures of horseshoe crabs Tachypleus tridentatus (juveniles) and Carcinoscorpius rotundicauda (juveniles and adults pooled) and their potential food sources at the basal level. The sources include seagrasses (Zostera japonica and Halophia beccarii), mangroves (Avicennia marina, Aegiceras corniculatum, Kandelia obovata, and Bruguiera gymnorrhiza), and sediment particulate organic matter (SPOM)

\section{Trophic position of horseshoe crabs}

Applying the MixSIAR mixing model and assuming a $3 \%$ enrichment of the $\delta^{15} \mathrm{~N}$ signature through each trophic shift, all of the horseshoe crabs examined had an estimated trophic position between primary and secondary consumer levels (see also Table A2).

\section{DISCUSSION}

$\delta^{13} \mathrm{C}$ signatures in tissues of Tachypleus tridentatus and Carcinoscorpius rotundicauda varied between species and among life stages within species, with

Table 4. Percent contributions (\%) of mangrove, seagrass, and sediment particulate organic matter (POM) at the basal level to the diet of horseshoe crabs Tachypleus tridentatus and Carcinoscorpius rotundicauda calculated by the MixSIAR mixing model (Stock \& Semmens 2013) and expressed as median values. Mangrove I consists of a mix of Aegiceras corniculatum, Avicennia marina, and Kandelia obovata. Mangrove II consists of Bruguiera gymnorrhiza

\begin{tabular}{|lcc|}
\hline Basal food sources & T. tridentatus & C. rotundicauda \\
\hline Mangrove I & 0.2 & 0.4 \\
Mangrove II & 0.5 & 2.2 \\
Zostera japonica & 62.6 & 58.6 \\
Halophila beccarii & 0.1 & 0.3 \\
Sediment POM & 35.3 & 35.6 \\
\hline
\end{tabular}

the greatest differences occurring among life stages. Because consumers tend to utilize food that is produced in the habitat in which they reside (Deegan \& Garritt 1997), it is likely that the different stable isotope values (particularly carbon) in horseshoe crabs at different life stages reflected different foraging sites in different sections of Pearl Bay and the adjacent coast as juveniles moved during maturation. The large intertidal sandand mudflats, where seagrasses are present, are known to serve as nursery grounds for juveniles of the 2 horseshoe crab species, while mangrove swamps serve as spawning areas for only $C$. rotundicauda (Chen et al. 2015). These differences in habitat use along with the isotopic carbon signature of seagrasses, POM and mangroves (Table A2) may explain the observed depletion of $\delta^{13} \mathrm{C}$ in younger juvenile and adult instars of $C$. rotundicauda.

T. tridentatus sub-adults must depart from their nursery grounds within the bay to seek and reach maturation sites in deeper channels along the coasts adjacent to the bay until they become mature and return to spawn on the bay's sandy beaches, spending most time among relatively enriched seagrass carbon sources (Chen et al. 2015). In contrast, $C$. rotundicauda does not migrate to the sea but spends its entire life within the bay (Chen et al. 2004, 2015, Davidson et al. 2008, Cartwright-Taylor \& Hsu 2012, Cartwright-Taylor et al. 2012). Their life stage-specific habitat use suggests that different sections of the bay and the adjacent coast have food items which $T$. tridentatus and $C$. rotundicauda at different instars can rely upon. A similar phenomenon was recorded in the fiddler crab Uca arcuata and the polychaete Neanthes glandicincta. Different conspecific individuals of these 2 species lived in different microhabitats and accessed different food sources within a mangrove swamp, thus having different $\delta^{13} \mathrm{C}$ signatures (Hsieh et al. 2002). Our data suggest that life-stage specific feeding needs are tightly bound to habitats utilized by the 2 co-occurring horseshoe crab species and that these differences were reflected in life-stage and species-specific $\delta^{13} \mathrm{C}$ signatures.

Maternally inherited nutrition may affect the $\delta^{13} \mathrm{C}$ signature observed in younger juvenile $T$. tridentatus and C. rotundicauda. The first instar stage of horseshoe crabs does not forage, but assimilates nutrition from the yolk. Accordingly, a previous study on $L i-$ mulus polyphemus found that newly hatched horse- 
shoe crabs bear $\delta^{13} \mathrm{C}$ and $\delta^{15} \mathrm{~N}$ signatures similar to adults, consistent with reliance on yolk (Gaines et al. 2002). When horseshoe crabs begin to independently forage at nursery grounds, this parental influence decreases, and instars take on the signatures of locally available foods. Based on the life-stage-specific habitat use in T. tridentatus and C. rotundicauda in Pearl Bay, the influences of location-associated food provision to adults may be closely related to vegetation distribution patterns (Chen et al. 2015). Therefore, we expect that gravid T. tridentatus adults returning from the sea to spawn in bays and coasts reflect and transmit a combination of relatively enriched marine $\left(\delta^{13} \mathrm{C}\right.$ : ca. $-21 \%$, Fry \& Sherr 1984, Hsieh et al. 2000) and seagrass isotopic carbon signals (Zostera japonica $\delta^{13} \mathrm{C}$ : ca. $-13 \%$, Table A2) to their eggs and hatched instars until the yolk is depleted. In contrast, C. rotundicauda adults are expected to reflect lighter estuarine signals (sediment POM $\delta^{13} \mathrm{C}$ : ca. $-22 \%$, Table A2). The speciesspecific differences in $\delta^{13} \mathrm{C}$ measured at the smallest instar stages in this study seem to follow this pattern, with $T$. tridentatus instars 5 to 6 having heavier $\delta^{13} \mathrm{C}$ values than C. rotundicauda instars 6 to 7 (both representing prosomal width at $20-30 \mathrm{~mm}$ sized animals). This finding suggests that the nutritional sources of younger $T$. tridentatus juveniles were probably associated with marine and coastal carbon sources that were assimilated by their parents, while young $C$. rotundicauda were reliant on carbon from estuarine habitats that were mixed with local sediment POM. However, these speculations need to be confirmed by future analyses of eggs and instar stages 1 to 4 .

The similarity of stable isotope ratios in intermediate sized instars ( 7 to 9 ) was likely due to overlapping habitat and diet use among these age classes. Juvenile $T$. tridentatus and juvenile C. rotundicauda co-occurred in some habitats within Pearl Bay; however, T. tridentatus was more abundant in more seaward, energetic environments, whereas $C$. rotundicauda aggregated at the mangrove forest edges in more landward estuarine areas (Chen et al. 2015). Such differences in microhabitat appear to affect the accessibility to carbon sources derived from coastal seagrasses or estuarine POM among these instars.
Comparing published data on the diet of juvenile $T$. tridentatus distributed in eastern Beibu Gulf with that in Hong Kong, we found horseshoe crabs appeared to consume similar food and occupy similar secondary consumer levels at these different sites (primarily bivalves, crustaceans, and polychaetes; $\mathrm{Hu}$ 2011, Kwan et al. 2015). These trophic positions agree with previous studies (Gaines et al. 2002, Carmichael et al. 2004). However, the $\delta^{15} \mathrm{~N}$ values of T. tridentatus in Hong Kong were enriched by 2.4 to $3.1 \%$ compared to those on the east and west coasts (Pearl Bay) of Beibu Gulf (Fig. 5). The concentration of dissolved inorganic nitrogen reported from China's Pearl River Delta (236 $\mu \mathrm{M}$; Harrison et al. 2008), of which Hong Kong receives the outflow, is approximately 18 -fold higher than on either the east or west coasts of Beibu Gulf $(12.8 \mu \mathrm{M}$ in Pearl Bay, western Beibu Gulf, Meng \& Qin 2009; $11.4 \mu \mathrm{M}$ in eastern Beibu Gulf, Lan et al. 2014). Excessive nitrogen loading to the environment from residential, agricultural, or aquaculture wastes can alter the $\delta^{15} \mathrm{~N}$ signals in food webs (McClelland et al. 1997, McClelland \& Valiela 1998, Lefebvre et al. 2007). In New England waters, the horseshoe crab L. polyphemus and its prey became more enriched in $\delta^{15} \mathrm{~N}$ as the total anthropogenic nitrogen load to the habitat increased (Carmichael et al. 2004). These data sug-

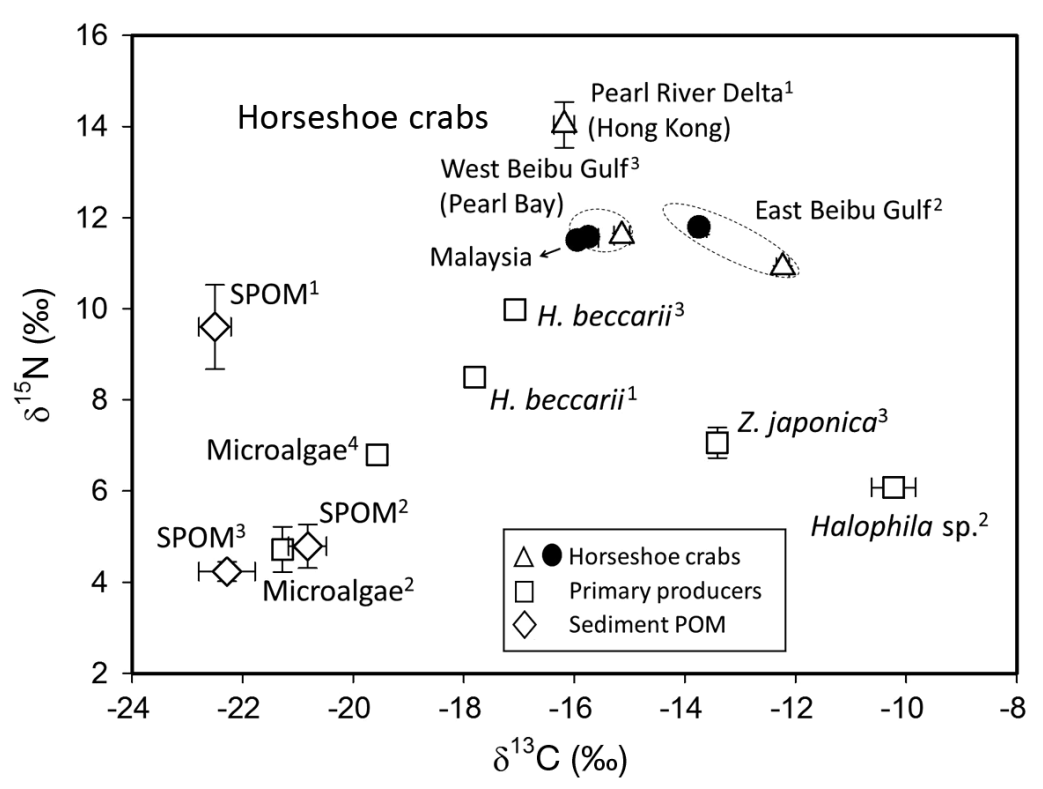

Fig. 5. Dual isotope plots of the $\delta^{13} \mathrm{C}$ and $\delta^{15} \mathrm{~N}$ signatures of the horseshoe crabs Tachypleus tridentatus (juveniles) and Carcinoscorpius rotundicauda (juveniles and adults pooled) and their potential food sources at the basal level in distantly separated habitats located in south China and Malaysia. Data sources - ${ }^{1}$ : Pearl River Delta (Hong Kong) from Kwan et al. (2015); 2: east Beibu Gulf from Hu (2011); ${ }^{3}$ : west Beibu Gulf (Pearl Bay) from the present study; ${ }^{4}$ : Malaysia from Newell et al. (1995) 
gest that the heavier $\delta^{15} \mathrm{~N}$ signal found in Hong Kong could be due to higher anthropogenic nitrogen inputs to the Pearl River Delta, rather than as a result of horseshoe crabs in this location feeding at a higher trophic level.

Our results reveal that at the basal level, seagrassderived ( $Z$. japonica) carbon made the greatest contribution to the diet of the 2 horseshoe crab species, T. tridentatus and C. rotundicauda. This finding is consistent with previous studies, which showed that the local seagrass Halophila beccarii supports juvenile $T$. tridentatus in Hong Kong and that another seagrass Halophila species is an important dietary source for $T$. tridentatus and $C$. rotundicauda in the eastern Beibu Gulf (Fig. 5; Hu 2011, Kwan et al. 2015). Benthic microalgae may be an alternative potential food source for horseshoe crabs, because they are a component of sediment POM, which also contributed to diet (Fig. 5). Sediment POM is likely comprised of a combination of benthic microalgae and detrital particles from seagrass and mangroves as well as settled terrestrial and estuarine particles. These mixed materials could have a combined stable isotope ratio near the values of sediment POM measured in this study. Sediment contribution needs to be assessed more thoroughly among different habitats to fully understand the contribution to horseshoe crab diet at different life stages.

\section{Conclusion}

The 2 Asian horseshoe crab species, T. tridentatus and $C$. rotundicauda, primarily relied on the seagrass-derived nutrients from local vegetated estuarine and coastal habitats throughout their life stages. Relatively small differences in $\delta^{13} \mathrm{C}$ values in the horseshoe crabs in Pearl Bay reflected important differences in habitat use between species and among life stages within species. These differences can be explained by 2 major effects, (1) life-stage specific feeding needs, and (2) the spatial distribution of seagrass seaward compared to more landward estuarine particulate organic matter in sediments on the large intertidal sand-mud flats. Our data suggest that loss of seagrass would result in the deterioration of habitat and food resources for Asian horseshoe crabs. Thus, protection of seagrass beds in bays and coasts is likely to be a requirement for conserving these threatened horseshoe crabs, especially in urbanized areas. In addition, our data provide a useful framework for planning the conservation of the horseshoe crabs by identifying habitats and associated food sources to be designated as protected areas. Sandy and muddy tidal flats that support seagrasses and adjacent mangrove swamps that provide breeding habitat should be incorporated in the protected areas.

Acknowledgements. The authors thank the anonymous reviewers who greatly improved this manuscript. The authors are grateful to Yongze Xing, Zhinan Su, Mingliu Yang, and Lingyu Huang for their field and laboratory support. This research was supported by the Open Research Fund of Guangxi Key Laboratory of Mangrove Conservation and Utilization under GKLMC-201304 and the National Natural Science Foundation of China under 41466003. The study fully complies with the current laws of China regarding research ethics and animal welfare.

\section{LITERATURE CITED}

Carmichael RH, Rutecki D, Annett B, Gaines E, Valiela I (2004) Position of horseshoe crabs in estuarine food webs: $\mathrm{N}$ and $\mathrm{C}$ stable isotopic study of foraging ranges and diet composition. J Exp Mar Biol Ecol 299:231-253

Carmichael RH, Gaines E, Sheller Z, Tong A, Clapp A, Valiela I (2009) Diet composition of juvenile horseshoe crabs: implications for growth and survival of natural and cultured stocks. In: Tanacredi JT, Botton ML, Smith DR (eds) Biology and conservation of horseshoe crabs. Springer, New York, NY, p 521-534

Cartwright-Taylor L, Hsu CC (2012) Follow-up study on population structure and breeding pattern of the mangrove horseshoe crab Carcinoscorpius rotundicauda in Singapore. Aquat Biol 14:217-222

* Cartwright-Taylor L, Ng HH, Goh TY (2012) Tracked mangrove horseshoe crab Carcinoscorpius rotundicauda remain resident in a tropical estuary. Aquat Biol 17: 235-245

Chatterji A, Mishra JK, Parulekar AH (1992) Feeding behaviour and food selection in the horseshoe crab, Tachypleus gigas (Müller). Hydrobiologia 246:41-48

Chen CP, Yeh HY, Lin PF (2004) Conservation of the horseshoe crab at Kinmen, Taiwan: strategies and practices. Biodivers Conserv 13:1889-1904

Chen CP, Yang MC, Fan LF, Qiu G, Liao YY, Hsieh HL (2015) Co-occurrence of juvenile horseshoe crabs Tachypleus tridentatus and Carcinoscorpius rotundicauda in an estuarine bay, Southwestern China. Aquat Biol 24: $117-126$

Davidson GWH, Ng PKL, Ho HC (2008) The Singapore Red Data Book: threatened plants and animals of Singapore. The Nature Society (Singapore), Singapore

* Deegan LA, Garritt RH (1997) Evidence for spatial variability in estuarine food webs. Mar Ecol Prog Ser 147:31-47

* France R, Chandler M, Peters R (1998) Mapping trophic continua of benthic food webs: body size $-\delta^{15} \mathrm{~N}$ relationships. Mar Ecol Prog Ser 174:301-306

Fry B, Sherr EB (1984) $\delta^{13} \mathrm{C}$ measurements as indicators of carbon flow in marine and freshwater ecosystems. Contrib Mar Sci 27:13-47

Gaines EF, Carmichael RH, Grady SP, Valiela I (2002) Stable isotopic evidence for changing nutritional sources of juvenile horseshoe crabs. Biol Bull 203:228-230 
Harrison PJ, Yin K, Lee JHW, Gan J, Liu H (2008) Physicalbiological coupling in the Pearl River Estuary. Cont Shelf Res 28:1405-1415

Hentschel BT (1998) Intraspecific variations in $\delta^{13} \mathrm{C}$ indicate ontogenetic diet changes in deposit-feeding polychaetes. Ecology 79:1357-1370

Hollander M, Wolfe DA (1999) Nonparametric statistical methods, 2nd edn. J. Wiley, New York, NY

Hsieh HL, Kao WY, Chen CP, Liu PJ (2000) Detrital flows through the feeding pathway of the oyster (Crassostrea gigas) in a tropical shallow lagoon: $\delta^{13} \mathrm{C}$ signals. Mar Biol 136:677-684

Hsieh HL, Chen CP, Chen YG, Yang HH (2002) Diversity of benthic organic matter flows through polychaetes and crabs in a mangrove estuary: $\delta^{13} \mathrm{C}$ and $\delta^{34} \mathrm{~S}$ signals. Mar Ecol Prog Ser 227:145-155

$\mathrm{Hu} \mathrm{M}$ (2011) Aspects of ecology and biology of two sympatric horseshoe crab species (Tachypleus tridentatus and Carcinoscorpius rotundicauda). PhD thesis, Department of Biology and Chemistry, City University of Hong Kong

*IUCN (2012) WCC-2012-Res-030-EN - The conservation of Asian horseshoe crabs. In: Resolutions and recommendations. IUCN, Gland, Switzerland, p 41-43. http://cms data.iucn.org/downloads/resolutions_and_recommen dations__in_english.pdf (accessed 14 January 2017)

K Kwan BKY, Cheung SG, Shin PKS (2015) A dual stable isotope study for diet composition of juvenile Chinese horseshoe crab Tachypleus tridentatus (Xiphosura) on a seagrass-covered intertidal mudflat. Mar Biol 162: 1137-1143

Lan WL, Li TS, Han LJ (2014) Distribution and seasonal variation of nutrient water of Tieshangang bay in Guangxi. Mark Sci 38:63-69 (in Chinese with English abstract)

* Lefebvre S, Clement JC, Pinay G, Thenail C, Durand P, Marmonier P (2007) ${ }^{15} \mathrm{~N}$-nitrate signature in low-order streams: effects of land cover and agricultural practices. Ecol Appl 17:2333-2346

McClelland JW, Valiela I (1998) Changes in food web structure under the influence of increased anthropogenic nitrogen inputs to estuaries. Mar Ecol Prog Ser 168:259-271

McClelland JW, Valiela I, Michener RH (1997) Nitrogenstable isotope signatures in estuarine food webs: a record of increasing urbanization in coastal watersheds. Limnol Oceanogr 42:930-937

Meng ZJ, Qin YY (2009) The water environment status and evaluation in the sea area of Zhenzhu Bay. J Anhui Agr Sci 37:14845-14847 (in Chinese with English abstract)

Morton B, Lee C (2010) Spatial and temporal distributions of juvenile horseshoe crabs (Arthropoda: Chelicerata) approaching extirpation along the northwestern shoreline of the New Territories of Hong Kong SAR, China. J Nat Hist 45:227-251

Newell RIE, Marshall N, Sasekumar A, Chong VC (1995) Relative importance of benthic microalgae, phytoplankton, and mangroves as sources of nutrition for penaeid prawns and other coastal invertebrates from Malaysia. Mar Biol 123:595-606
Parnell AC, Inger R, Bearhop S, Jackson AL (2010) Source partitioning using stable isotopes: coping with too much variation. PLOS ONE 5:e9672

Peterson BJ, Fry B (1987) Stable isotopes in ecosystem studies. Annu Rev Ecol Syst 18:293-320

Post DM (2002) Using stable isotopes to estimate trophic position: models, methods, and assumptions. Ecology 83: 703-718

Qiu GL, Fan HQ, Li ZS, Liu GH, Shi YJ, Li S (2013) Population dynamics and seed banks of the threatened seagrass Halophila beccarii in Pearl Bay, Guangxi. Acta Ecol Sin 33:6163-6172 (in Chinese with English abstract)

Qiu GL, Fan HQ, Li LX, Li S (2014a) Restorations of the intertidal seagrass beds. China Forestry Publishing House, Beijing, p 31-34 (in Chinese)

Qiu GL, Fan HQ, Liu GH, Kaiser D, Unger D, Zhou HL (2014b) Carbon and nitrogen content and stable isotope ratios of mangrove, mudflat and seagrass systems. In: Chu TJ, Lee YC (eds) The 5th Conference on Taiwan Wetland Ecology. Taiwan Wetland Society, Hsinchu, Taiwan, p 81-84 (Chinese and English abstract)

* Rau GH, Sweeney RE, Kaplan IR, Mearns AJ, Young DR (1981) Differences in animal ${ }^{13} \mathrm{C}_{1}{ }^{15} \mathrm{~N}$ and D abundance between a polluted and an unpolluted coastal site: likely indicators of sewage uptake by a marine food web. Estuar Coast Shelf Sci 13:701-707

Records of bays in China (1993) Bays in Guangxi. In: China Bay Editing Commission (ed) Records of bays in China, Vol 12. China Ocean Press, Beijing, p 268-313 (in Chinese)

* Rodelli MR, Gearing JN, Gearing PJ, Marshall N, Sasekumar A (1984) Stable isotope ratio as a tracer of mangrove carbon in Malaysian ecosystems. Oecologia 61:326-333

SAS Institute (2003) SAS User's Guide: Statistics, Release 9.1. SAS Institute, Cary, NC

Sekiguchi K (1988) Ecology. In: Sekiguchi K (ed) Biology of horseshoe crabs. Science House, Tokyo, p 50-68

Sekiguchi K, Yamamichi Y, Seshimo H, Sugita H (1988) Normal development. In: Sekiguchi K (ed) Biology of horseshoe crabs. Science House, Tokyo, p 133-224

Shin PKS, Li HY, Cheung SG (2009) Horseshoe crabs in Hong Kong: current population status and human exploitation. In: Tanacredi JT, Botton ML, Smith DR (eds) Biology and conservation of horseshoe crabs. Springer, New York, NY, p 347-360

Stock B, Semmens B (2013) MixSIAR GUI user manual. Version 3.1. https://github.com/brianstock/MixSIAR/.

Zadeh SS, Christianus A, Saad CR, Hajeb P, Kamarudin MS (2009) Comparisons in prosomal width and body weight among early instar stages of Malaysian horseshoe crabs, Carcinoscorpius rotundicauda and Tachypleus gigas, in the laboratory. In: Tanacredi JT, Botton ML, Smith DR (eds) Biology and conservation of horseshoe crabs. Springer, New York, NY, p 267-274

Zhou H, Morton B (2004) The diets of juvenile horseshoe crabs, Tachypleus tridentatus and Carcinoscorpius rotundicauda (Xiphosura), from nursery beaches proposed for conservation in Hong Kong. J Nat Hist 38: 1915-1925 
Appendix. Additional data are provided to summarize (1) the identification of instar stages of the 2 co-occurring horseshoe crab species Tachypleus tridentatus and Carcinoscorpius rotundicauda, and (2) the stable carbon and nitrogen isotopic values of these horseshoe crabs, sediment particulate organic matter and primary producers, including mangroves and seagrasses, sampled from Pearl Bay, Guangxi, PR China

Table A1. Summary of the identification of instar stages in Tachypleus tridentatus and Carcinoscorpius rotundicauda with prosomal widths ( $\mathrm{mm}$ ) and the number of individuals used for constructing the size-associated growth curves and subsequently assessing the life-stage changes of the $\delta^{13} \mathrm{C}$ and $\delta^{15} \mathrm{~N}$ signatures through different instar stages. The data set is the same as used in Fig. 2. The subsample is a subset of all samples, and is the major data set used in the present study. The rearing data are used as reference baselines for identifying instar stages. Rearing data of T. tridentatus are from C.-P. Chen and H.-L. Hsieh (unpubl. data). Data of C. rotundicauda are from Zadeh et al. (2009). (-) Sample sizes not available

\begin{tabular}{|c|c|c|c|c|c|c|c|c|}
\hline \multirow[t]{2}{*}{ Stage } & \multirow[b]{2}{*}{$\mathrm{n}$} & \multirow{2}{*}{$\begin{array}{l}\text { Rearing data } \\
\text { Mean } \pm \text { SE }(\mathrm{mm})\end{array}$} & \multicolumn{3}{|c|}{ All samples } & \multicolumn{3}{|c|}{ Subsamples } \\
\hline & & & $\mathrm{n}$ & Min. & Max. & $\mathrm{n}$ & Min. & Max. \\
\hline \multicolumn{9}{|l|}{ T. tridentatus } \\
\hline 5 & 10 & $21.2 \pm 0.09$ & 3 & 19.9 & 23.4 & 2 & 19.9 & 23.1 \\
\hline 6 & 30 & $26.7 \pm 0.03$ & 24 & 24.9 & 31.6 & 9 & 24.9 & 31.6 \\
\hline 7 & 30 & $35.1 \pm 0.03$ & 13 & 34.1 & 38.4 & 5 & 34.6 & 38.4 \\
\hline 8 & 25 & $44.9 \pm 0.05$ & 13 & 38.9 & 55.2 & 10 & 39.2 & 55.2 \\
\hline $9-10$ & 29 & $62.0 \pm 0.13$ & 9 & 59.6 & 69.4 & 7 & 59.6 & 69.4 \\
\hline \multicolumn{9}{|c|}{ C. rotundicauda } \\
\hline 6 & - & 17.1 & 4 & 16.7 & 20.0 & 4 & 16.7 & 20.0 \\
\hline 7 & - & 23.4 & 41 & 21.8 & 29.6 & 12 & 21.8 & 29.6 \\
\hline 8 & - & $31.8^{\mathrm{a}}$ & 41 & 30.6 & 37.3 & 17 & 30.6 & 36.9 \\
\hline 9 & - & $43.3^{\mathrm{a}}$ & 7 & 39.4 & 46.6 & 5 & 41.8 & 46.1 \\
\hline 10 & - & $58.8^{\mathrm{a}}$ & 12 & 50.3 & 66.0 & 9 & 49.5 & 66.0 \\
\hline 11 & - & $80.0^{\mathrm{a}}$ & 4 & 71.5 & 74.1 & 3 & 71.5 & 74.1 \\
\hline $12+13$ (Adult) & & & 3 & 121.1 & 156.4 & 3 & 121.1 & 156.4 \\
\hline
\end{tabular}

Table A2. Summary of the signatures of $\delta^{13} \mathrm{C}$ and $\delta^{15} \mathrm{~N}$ in the horseshoe crabs Tachypleus tridentatus and Carcinoscorpius rotundicauda, sediment particulate organic matter (POM) and primary producers

\begin{tabular}{|c|c|c|c|c|c|c|c|c|}
\hline \multirow[t]{2}{*}{ Site or taxa } & \multicolumn{4}{|c|}{$\delta^{13} \mathrm{C}(\%)$} & \multicolumn{4}{|c|}{$\delta^{15} \mathrm{~N}(\%)$} \\
\hline & $\mathrm{n}$ & Min. & Max. & Mean $\pm \mathrm{SE}$ & $\mathrm{n}$ & Min. & Max. & Mean $\pm \mathrm{SE}$ \\
\hline T.tridentatus & 33 & -16.7 & -13.7 & $-15.1 \pm 0.1$ & 33 & 10.6 & 12.2 & $11.6 \pm 0.1$ \\
\hline C. rotundicauda & 53 & -18.5 & -13.6 & $-15.8 \pm 0.2$ & 53 & 10.8 & 13.5 & $11.6 \pm 0.1$ \\
\hline Sediment POM & 13 & -24.7 & -19.3 & $-22.3 \pm 0.5$ & 13 & 2.5 & 5.2 & $4.2 \pm 0.2$ \\
\hline \multicolumn{9}{|l|}{ Primary producer } \\
\hline Mangrove I & 14 & & & $-29.1 \pm 0.2$ & 14 & & & $5.8 \pm 0.1$ \\
\hline Aegiceras corniculatum & 5 & -30.7 & -28.6 & & 5 & 5.3 & 6.9 & \\
\hline Avicennia marina & 5 & -29.8 & -28.2 & & 5 & 5.5 & 6.3 & \\
\hline Kandelia obovata & 4 & -29.4 & -28.6 & & 4 & 5.4 & 5.8 & \\
\hline \multicolumn{9}{|l|}{ Mangrove II } \\
\hline Bruguiera gymnorrhiza & 4 & -30.5 & -28.5 & $-29.4 \pm 0.4$ & 4 & 2.9 & 4.8 & $4.1 \pm 0.4$ \\
\hline \multicolumn{9}{|l|}{ Seagrass } \\
\hline Zostera japonica & 18 & -14.3 & -11.7 & $-13.4 \pm 0.1$ & 16 & 5.0 & 9.1 & $7.1 \pm 0.3$ \\
\hline Halophila beccarii & 6 & -17.2 & -17.0 & $-17.1 \pm 0.0$ & 4 & 9.8 & 10.1 & $10.0 \pm 0.1$ \\
\hline
\end{tabular}

Editorial responsibility: Judith Grassle, New Brunswick, New Jersey, USA
Submitted: August 4, 2016; Accepted: December 12, 2016 Proofs received from author(s): January 26, 2017 